\title{
Polymorphisms in APOA1 and $L P L$ genes are statistically independently associated with fasting TG in men with CAD
}

\author{
Olga W Souverein*,1, J Wouter Jukema ${ }^{2}$, S Matthijs Boekholdt ${ }^{3}$, Aeilko H Zwinderman ${ }^{1}$ and $^{*}$ \\ Michael WT Tanck ${ }^{1}$
}

\author{
${ }^{1}$ Department of Clinical Epidemiology and Biostatistics, Academic Medical Center, Amsterdam, The Netherlands; \\ ${ }^{2}$ Department of Cardiology, Leiden University Medical Center, Leiden, The Netherlands; ${ }^{3}$ Department of Cardiology, \\ Academic Medical Center, Amsterdam, The Netherlands
}

The objective of this paper was to identify the single nucleotide polymorphisms (SNPs) that show unshared effects on plasma triglyceride (TG) levels and to investigate whether these SNPs show statistically independent effects on plasma TG levels. In total, 59 polymorphisms in $\mathbf{2 0}$ genes involved in lipid metabolism were investigated. Polymorphisms were selected for a multivariate ANOVA model if they showed an univariate association with TG (after adjustment for HDL-C and LDL-C) in more than $50 \%$ of bootstrap samples that were made from the original data. The multivariate model included 512 men with coronary artery disease from the REGRESS study who were completely genotyped for eight polymorphisms selected in the univariate procedure (ie, APOA1 G(-75)A, ABCA1 C (-477)T, ABCA1 G1051A, APOC3 T3206G, APOE Arg158Cys, LIPC C $(-514) \mathrm{T}$, LPL Asn291Ser and LPL Ser447Stop). The gene variants APOA1 G $(-75) A(P=0.04)$ and $L P L$ Asn291Ser $(P=0.03)$ were significantly associated with plasma TG levels in this multivariate analysis. The eight polymorphisms explained $8.9 \%$ of the variation in plasma TG levels. In conclusion, this study showed statistically independent effects of gene variants in the APOA1 and LPL genes on fasting plasma levels of TG. Nevertheless, only a small part of variation in TG levels could be explained by the polymorphisms. European Journal of Human Genetics (2005) 13, 445-451. doi:10.1038/sj.ejhg.5201362

Published online 19 January 2005

Keywords: polymorphisms; triglycerides; coronary artery disease; association study

Introduction

High plasma triglyceride (TG) levels are a risk factor for coronary artery disease. ${ }^{1}$ The regulation of TG levels, and fat metabolism in general is a complex process in which many enzymes, receptors and proteins play a role. For a more elaborate description of the TG level regulation, we refer to Gurr ${ }^{2}$ and Mead et al. ${ }^{3}$ In short, the major carrier of

*Correspondence: Ms OW Souverein, Department of Clinical Epidemiology and Biostatistics, Academic Medical Center, Room J1B-207-1, PO Box 22700, 1100 DE Amsterdam, The Netherlands. Tel: +31 20566 6945; Fax: + 3120 6912683; E-mail: o.w.souverein@amc.uva.nl Received 14 September 2004; revised 2 November 2004; accepted 24 November 2004 triglycerides in (fasting) blood is very-low-density lipoprotein (VLDL), which is mainly secreted by the liver. ${ }^{2}$ TG from VLDL is hydrolysed by lipoprotein lipase (LPL), which is associated with capillaries mostly in muscle and adipose tissue. ${ }^{3}$ The cells of these tissues take up fatty acids and VLDL is degraded to intermediate density lipoprotein (IDL) and by further hydrolysis to low-density lipoprotein (LDL). 2,3 VLDL, like all lipoproteins, is coated with phospholipids and apolipoproteins. ${ }^{2}$ These apolipoproteins stabilize lipids in an aqueous environment and recognize and interact with specific receptors on cell surfaces. $^{2}$ There are a number of enzymes (eg LPL, CETP, PLTP, LCAT), transport proteins (eg ABCA1) and receptors 
(eg SR-B1, LDL-receptor) that play an important role in the transport and metabolism of TG and cholesterol. ${ }^{2,4-6}$

Fasting TG levels vary considerably between individuals. This variation can be explained by a combination of environmental and genetic factors. Twin studies have estimated the heritability of TG to be more than $50 \%$ (reviewed by Snieder et $\mathrm{al}^{7}$ ). Several studies have investigated the effect of different polymorphisms on plasma TG levels eg. ${ }^{8-10}$ However, these studies were usually restricted to one gene and one or a few polymorphisms within a gene. Whereas, given the complexity of TG regulation, many genes probably play a role. Some of these genes probably show (pleiotropic) effects on TG as well as on HDL-C or LDL-C (which we call shared genes), while others do not (which we call unshared genes). In this study we are interested in the effects of unshared genes. Arya et al ${ }^{11}$ show that in univariate linkage analysis, the power to detect the unshared genes can be increased by incorporating other correlated traits as covariates. In this view, covariates are used to intensify a genetic effect that may be hidden by the relationship between the phenotype and the covariate. ${ }^{12}$ The same is true for association studies where the power of detecting association between an unshared gene (polymorphism) and a phenotype can be increased by reducing residual variation through including correlated traits as covariates. ${ }^{13}$ The present study was conducted to identify the single nucleotide polymorphisms (SNPs) that show unshared effects on plasma TG levels and to investigate whether these SNPs show statistically independent effects (ie, effects not caused by linkage disequilibrium (LD)) on plasma TG levels.

\section{Methods}

Study population

The REGRESS study was a double-blind, placebo-controlled, multicentre trial to assess the effects of pravastatin on progression and regression of angiographically documented coronary atherosclerosis. The study consisted of 884 unrelated Dutch male patients with serum cholesterol between 4 and $8 \mathrm{mmol} / \mathrm{l}$ and TG levels lower than $4.0 \mathrm{mmol} / \mathrm{l}$. Details of the study design have been reported previously. ${ }^{14}$

\section{Selection of genes/polymorphisms}

Many polymorphisms in different candidate genes for cardiovascular disease have been determined in the REGRESS study. We identified 20 (candidate) genes that are reported to be involved in lipid metabolism. The 59 polymorphisms that were available in these 20 genes and for which at least 600 patients had been genotyped, were analysed in the present study (see Table 1).
Table 1 The 59 polymorphisms examined in this study

\begin{tabular}{|c|c|c|c|}
\hline Gene & Polymorphism & $\begin{array}{l}\text { Frequency of } \\
\text { least common } \\
\text { allele }\end{array}$ & $\begin{array}{c}\% \text { bootstrap } \\
\text { samples where } \\
P<0.05\end{array}$ \\
\hline \multirow[t]{2}{*}{$A P O A 1$} & $G(-75) A$ & 0.105 & 86.2 \\
\hline & $\mathrm{C} 83 \mathrm{~T}$ & 0.029 & 12.5 \\
\hline \multirow{6}{*}{ APOC 3} & $C(-641) A$ & 0.421 & 18.7 \\
\hline & $\mathrm{C}(-482) \mathrm{T}$ & 0.246 & 10.7 \\
\hline & $\mathrm{T}(-455) \mathrm{C}$ & 0.339 & 6.7 \\
\hline & C1100T & 0.260 & 29.1 \\
\hline & C3175G (Sstl) & 0.087 & 12.3 \\
\hline & T3206G & 0.336 & 61.5 \\
\hline \multirow[t]{2}{*}{ APOA4 } & Thr347Ser & 0.169 & 10.1 \\
\hline & Gln $360 \mathrm{His}$ & 0.080 & 37.6 \\
\hline \multirow[t]{2}{*}{ APOA5 } & $\mathrm{T}(-1131) \mathrm{C}$ & 0.070 & 42.3 \\
\hline & Ser19Trp & 0.072 & 36.5 \\
\hline \multirow[t]{2}{*}{$A P O B$} & Thr71lle & 0.288 & 16.0 \\
\hline & Arg3500GIn & 0.001 & 0.0 \\
\hline \multirow[t]{2}{*}{$A P O E$} & Cys112Arg & 0.167 & 9.9 \\
\hline & Arg158Cys & 0.072 & 85.6 \\
\hline \multirow[t]{8}{*}{$A B C A 1$} & $C(-477) T$ & 0.448 & 54.7 \\
\hline & C17G & 0.323 & 41.5 \\
\hline & G1051A & 0.255 & 89.1 \\
\hline & G2706A & 0.029 & 32.6 \\
\hline & $\mathrm{A} 2715 \mathrm{C}$ & 0.003 & 16.4 \\
\hline & G2868A & 0.080 & 3.0 \\
\hline & G3911C & 0.026 & 11.6 \\
\hline & G5155A & 0.259 & 30.9 \\
\hline \multirow[t]{10}{*}{ CETP } & $G(-2708) A$ & 0.310 & 14.1 \\
\hline & $G(-972) A$ & 0.490 & 7.6 \\
\hline & $C(-630) A$ & 0.079 & 6.6 \\
\hline & $\mathrm{C}(-629) \mathrm{A}$ & 0.437 & 9.6 \\
\hline & Ile405Val & 0.281 & 17.3 \\
\hline & Asp442Gly & 0.001 & 0.0 \\
\hline & CCC $784 A$ & 0.390 & 8.0 \\
\hline & ECONI & 0.532 & 6.8 \\
\hline & MSPI & 0.182 & 6.4 \\
\hline & TAQIB & 0.399 & 9.9 \\
\hline CYP7A1 & A278C & 0.374 & 10.7 \\
\hline LCAT & Ser208Thr & 0.030 & 16.1 \\
\hline \multirow[t]{3}{*}{$L D L R$} & C1959T & 0.449 & 11.4 \\
\hline & $\mathrm{NCOI}$ & 0.295 & 6.6 \\
\hline & TAQI & 0.090 & 11.4 \\
\hline \multirow[t]{2}{*}{ LIPC } & $\mathrm{T}(-710) \mathrm{C}$ & 0.213 & 49.3 \\
\hline & $C(-514) T$ & 0.213 & 66.5 \\
\hline \multirow[t]{2}{*}{$\angle P A$} & C93T & 0.118 & 6.0 \\
\hline & G121A & 0.124 & 29.1 \\
\hline \multirow[t]{6}{*}{$L P L$} & $\mathrm{~T}(-93) \mathrm{G}$ & 0.018 & 41.0 \\
\hline & Asp9Asn & 0.024 & 18.0 \\
\hline & Asn291Ser & 0.029 & 60.2 \\
\hline & Ser447Stop & 0.095 & 63.6 \\
\hline & HIND3 & 0.289 & 19.9 \\
\hline & PVUI & 0.491 & 36.2 \\
\hline MTP & $\mathrm{G}(-493) \mathrm{T}$ & 0.267 & 5.6 \\
\hline \multirow[t]{2}{*}{ PON1 } & Leu55Met & 0.367 & 25.1 \\
\hline & Gln192Arg & 0.290 & 41.3 \\
\hline PON2 & Ser311Cys & 0.234 & 12.3 \\
\hline \multirow{2}{*}{ PPARA } & G2176A & 0.078 & 4.7 \\
\hline & Leu162Val & 0.057 & 30.7 \\
\hline & Pro12Ala & 0.113 & 13.5 \\
\hline \multirow{3}{*}{ SCARB1 } & Gly2Ser & 0.086 & 5.2 \\
\hline & C1050T & 0.485 & 34.2 \\
\hline & Intron $5(\mathrm{C} / \mathrm{T})$ & 0.086 & 21.3 \\
\hline
\end{tabular}




\section{Biochemical and DNA analysis}

All lipid laboratory tests were carried out at the Lipid Reference Laboratory. Serum cholesterol, high-density lipoprotein cholesterol (HDL-C), and triglycerides were measured in fasting blood samples by standard techniques and LDL was calculated according to the Friedewald formula. $^{14}$

Within REGRESS, patients have been genotyped for several polymorphisms in genes associated with lipid metabolism. The genotypes were obtained as described earlier. $^{9,15-32}$

\section{Statistical analysis}

A $\chi^{2}$ test with one degree of freedom was performed to evaluate whether the genotype counts of the selected polymorphisms were different from those expected under Hardy-Weinberg equilibrium. Baseline TG values were logarithmically transformed to represent a normal distribution. All analyses were performed with the transformed values, but the geometric means and their 95\% confidence intervals (CI) are presented. All statistical analyses have been performed using the SAS System (version 8.2 for Windows). In general, genotyping of many polymorphisms leads to few completely genotyped individuals. In this study, the 59 available polymorphisms could not be analysed simultaneously in a multivariate model due to missing values (ie, too few completely genotyped patients were available). Therefore, a polymorphism selection process preceded the multivariate model. This was done in the following way, based on an idea of Hoh et al. ${ }^{33} \mathrm{~A}$ thousand bootstrap samples were made from the original data set. In each set, each polymorphism was tested for its effect on TG while the model was adjusted for HDL-C baseline and low-density lipoprotein cholesterol (LDL-C) baseline values (ie, to increase the power to detect unshared effects). A polymorphism was selected for further analyses if a statistically significant $(P<0.05)$ association was found in more than $50 \%$ of the bootstrap samples. The bootstrap method was used to minimize the effect of very influential patients and possible departures from ANOVA model. Thus, a more robust selection of polymorphisms was made. The selected polymorphisms were analysed together in a multivariate model, which was again adjusted for HDL-C and LDL-C. This was done, both in the patients from the original REGRESS study that were completely genotyped for the selected polymorphisms, as well as in the thousand bootstrap samples, similar to the univariate procedure. To evaluate whether possible loss of significance in the multivariate analyses was not just an effect of loss of patients compared to the univariate analyses, we also calculated the univariate $P$-value in the patients that were completely genotyped for the selected polymorphisms.

For the selected polymorphisms, all possible two-way gene-gene interactions were assessed by backward selec- tion. The main effect of the selected polymorphisms as well as HDL-C and LDL-C were forced into the model.

To examine whether the patients available for multivariate analysis differed from the others for baseline characteristics, comparisons between selected (ie, those that are completely genotyped for the polymorphisms in the multivariate model) and not selected individuals were made with $t$-tests for age, body mass index (BMI) and baseline lipid values (total cholesterol, HDL-C, LDL-C and TG) and with $\chi^{2}$ tests (or Fisher's exact where appropriate) for history of smoking, smoking presently, use of several drugs (ie, nitrates, beta blockers, CA inhibitors and ACE inhibitors) and genotype counts.

\section{Results}

A total of 59 polymorphisms have been examined in this study (Table 1). Eight polymorphisms were significantly associated with TG after adjustment for HDL-C and LDL-C in more than $50 \%$ of the bootstrap samples. These were APOA1 $\mathrm{G}(-75) \mathrm{A}, A B C A 1 \mathrm{C}(-477) \mathrm{T}, A B C A 1 \mathrm{G} 1051 \mathrm{~A}$, APOC3 T3206G, APOE Arg158Cys, LIPC C(-514)T, LPL Asn291Ser and LPL Ser447Stop. The eight polymorphisms were then analysed together in a multivariate analysis, which included a total of 512 men, who were completely genotyped for the eight polymorphisms. Their baseline characteristics are presented in Table 2. These 512 men were not statistically significantly different for age, BMI, total cholesterol, HDL-C, LDL-C and TG baseline levels, history of smoking, present smoking or intake of nitrates, beta blockers, CA inhibitors and ACE inhibitors, from the 372 men that were not available for multivariate analysis. Genotype counts of the eight polymorphisms selected for multivariate analyses differed between these two groups for APOA1 G $(-75)$ A $(P<0.001)$, but were comparable for the other polymorphisms. Except ABCA1 C(-477)T, ABCA1 G1051A and LPL Asn291Ser, the observed genotype counts were not statistically significantly different from those expected under Hardy-Weinberg equilibrium.

In the multivariate analysis APOA1 G $(-75) \mathrm{A}(P=0.04)$ and $L P L$ Asn291Ser $(P=0.03)$ were statistically significantly associated with TG (Table 3 ). These were also statistically

Table 2 Baseline characteristics of the patients in the multivariate analyses $(n=512)$

\begin{tabular}{lc}
\hline Characteristic & $\begin{array}{c}\text { Selected population } \\
(n=512)\end{array}$ \\
\hline Age (years) (mean \pm SD) & $55.8 \pm 8.0$ \\
BMI $\left(\mathrm{kg} / \mathrm{m}^{2}\right)($ mean \pm SD) & $26.0 \pm 2.7$ \\
Total cholesterol (mmol/l) (mean $\pm \mathrm{SD})$ & $6.0 \pm 0.9$ \\
$\mathrm{HDL}(\mathrm{mmol} / \mathrm{l})($ mean $\pm \mathrm{SD})$ & $0.9 \pm 0.2$ \\
$\mathrm{LDL}(\mathrm{mmol} / \mathrm{l})($ mean \pm SD) & $4.3 \pm 0.8$ \\
Triglycerides (mmol/I) (median (range)) & $1.7(3.6)$ \\
\hline
\end{tabular}


significantly associated in more than $50 \%$ of the multivariate analyses in the bootstrap samples and in the univariate analysis in the 512 complete cases (Table 3). APOC3 T3206G and LPL Ser447Stop were statistically significantly associated with TG in the univariate analysis in the 512 complete cases $(P=0.03$ and 0.02 respectively), but were not in the multivariate analyses. $A B C A 1$ $\mathrm{C}(-477) \mathrm{T}, A B C A 1 \mathrm{G} 1051 \mathrm{~A}$, APOE Arg158Cys and LIPC $\mathrm{C}(-514) \mathrm{T}$ were not statistically significantly associated with TG in the univariate analysis in the 512 complete cases or in the multivariate analyses (Table 3). Mean TG values (95\% CI) and number of cases per genotype for the eight polymorphisms are also presented in Table 3 . In the multivariate analysis, after correction for HDL-C and LDL$\mathrm{C}$, the polymorphisms explained $8.9 \%$ of the remaining variation of baseline TG values.

A statistically significant gene-gene interaction between $A B C A 1 \mathrm{C}(-477) \mathrm{T}$ and APOC3 T3206G $(P=0.03)$ was found. The other gene-gene interactions did not reach statistical significance. When this interaction was included in the multivariate model, the main effects of the polymorphisms and interaction together explained $11.1 \%$ of the remaining variation of baseline TG values.

Using the two statistically significantly associated polymorphisms (ie, APOA1 G(-75)A and LPL Asn291Ser), a distinction is possible between two genetic subgroups with clinically relevant differences in TG values. The 471 patients, who were homozygous wildtype or heterozygous for APOA1 $\mathrm{G}(-75) \mathrm{A}$ and homozygous wildtype for $L P L$ Asn291Ser, had mean TG level of $1.61 \mathrm{mmol} / \mathrm{l}$. In contrast, the 41 patients with at least one 'deleterious' genotype (ie, homozygous mutant for APOA1 G(-75)A or heterozygous or homozygous mutant for $L P L$ Asn291Ser) had average TG levels of $2.14 \mathrm{mmol} / \mathrm{l}$.

\section{Discussion}

This study investigated the effect of multiple SNPs on plasma TG levels. The APOA1 G(-75)A and LPL Asn291Ser polymorphisms were statistically independently related to plasma TG values. APOC3 T3206G (in LD with APOA1 $\mathrm{G}(-75) \mathrm{A})$ and $L P L$ Ser447Stop did not show independent effects. No firm conclusion can be drawn about $A B C A 1$ $\mathrm{C}(-477) \mathrm{T}, A B C A 1 \mathrm{G} 1051 \mathrm{~T}$, APOE Arg158Cys and LIPC $\mathrm{C}(-514) \mathrm{T}$, because their lack of significance in the multivariate model might be caused by loss of power. The bootstrapping method we used to identify polymorphisms with an unshared effect on TG does not account for polymorphisms that only have significant effects when taking into account the effect of other polymorphisms nor does it identify gene-gene interactions without marginal effects. These kinds of effects are likely in a biological system such as lipid metabolism, but the problem of 
missing data, which is very common in genetic association studies, prevented us from investigating these aspects.

To investigate whether the difference in genotype counts between selected and not selected cases for APOA1 $\mathrm{G}(-75) \mathrm{A}$ influenced the results, we performed multiple imputation of the missing genotypes of polymorphisms in all 686 patients of whom the APOA1 G(-75)A polymorphism was available, and subsequently we performed the same multivariate regression analysis on all 686 patients. We found again that APOA1 G(-75)A was statistically significantly associated with $\mathrm{TG}$ in this multivariate analysis and that parameter estimates were very similar to the parameter estimates from analysis with the set of 512 patients (data not shown). Therefore, we conclude that the effect of $A P O A 1 \mathrm{G}(-75) \mathrm{A}$ was estimated correctly.

Three of the eight polymorphisms (ie, $A B C A 1 \mathrm{C}(-477) \mathrm{T}$, $A B C A 1$ G1051A and LPL Asn291Ser) selected for the multivariate analyses showed deviations from HardyWeinberg equilibrium. In general, deviations from Hardy-Weinberg equilibrium may point to genotyping errors, subpopulation structure or they might occur when the study population is not a random selection of the general population. Since we observed an excess of heterozygotes instead of homozygotes, the deviations from Hardy-Weinberg equilibrium are unlikely caused by genotyping errors. Furthermore, if genotyping errors were present, this would probably decrease power to detect association, since genotyping errors introduce more noise. We checked whether subpopulation structure was present with the method of Pritchard et al, ${ }^{34}$ but this did not seem to be the case. The subjects in this study all have established coronary artery disease and, therefore, the study population is not a random selection of the general population. This might have caused deviations from Hardy-Weinberg equilibrium. Even so, these deviations from Hardy-Weinberg equilibrium are less relevant to our study since our statistical analyses nowhere assume Hardy-Weinberg equilibrium as we investigate genotype effects and not allele effects.

Homozygous carriers of the A allele in APOA1 G(-75)A showed higher levels of TG. This was also found by $\mathrm{Xu}$ et $\mathrm{al}^{35}$ but other studies found no association between APOA1 G(-75)A and TG levels. ${ }^{36,37}$ APOA1 G(-75)A is located in the promoter region of the $A P O A 1$ gene and could therefore influence the expression of the APOA1 gene. Whether this polymorphism is functional or in LD with a functional polymorphism is uncertain. A possible biological explanation of how this gene variation elevates plasma TG levels is that the binding capacity of the protein to lipases is impaired, resulting in decreased lipolysis and elevated plasma TG levels. On the other hand, Yamamoto et $a l^{38}$ showed that apolipoprotein C-III, apolipoprotein E and apolipoprotein A-I work as a potential inhibitor for the LPL-mediated lipolysis of TG-rich emulsions. This implies that elevated lipoprotein levels in blood lead to elevated
TG levels. For APOA1 $\mathrm{G}(-75) \mathrm{A}$, results concerning the effects of this SNP on apolipoprotein A-I levels are inconsistent. $^{24,36,39-41}$ In the present study, no data were available on plasma levels of apolipoproteins. Therefore, the association between the APOA1 G(-75)A polymorphism and plasma levels of apolipoproteins could not be studied.

In this study, carriers of the LPL Asn291Ser mutant allele showed higher levels of TG. Several studies found a similar association, ${ }^{8,42-44}$ while others did not find an association between LPL Asn291Ser and TG levels. ${ }^{45,46}$ Carriers of $L P L$ Asn291Ser are found to have modest decreases of LPL activity and higher TG levels. ${ }^{47}$ In the present study, data on LPL activity were available. Carriers of the least common allele in the LPL Asn291Ser polymorphism showed lower LPL activity, but this was not statistically significant $(P=0.17)$.

It is often found in association studies that effects of polymorphisms differ between men and women (eg by Dallongeville $e \mathrm{al}^{48}$ ) and between different ethnic groups. Therefore, generalization of the results to healthy individuals, women or ethnic groups other than Caucasian is difficult since this is a study with Caucasian male patients with established coronary artery disease. The sample of men with CAD was chosen, because high TG is a known risk factor for $\mathrm{CAD}$ and therefore, rare genotypes will probably have an increased prevalence in such a population. The fact that men were included in the study based on their baseline total cholesterol value poses another problem with generalization to the broad population. The patients all had screening total cholesterol levels between 4.0 and $8.0 \mathrm{mmol} / \mathrm{l}$ and therefore these men are not fully representative of the general population. The maximum TG value in the REGRESS population is $4.0 \mathrm{mmol} / \mathrm{l}$. However, using mean and SD for TG from the Framingham Offspring Study ${ }^{10}$ and the STANILAS cohort, ${ }^{49}$ it is estimated that only $2 \%$ of the population had fasting TG levels above $4 \mathrm{mmol} / \mathrm{l}$.

In this study, an explained variance of approximately $9 \%$ was found. This percentage is small compared to a heritability of more than $50 \%$ that is estimated by twin studies. To identify genes that have previously been associated with TG, we performed a search in Pubmed (MESH headings: polymorphism or mutation and triglycerides) and OMIN (keyword: triglyceride). This search identified 30 genes of which eight were not directly involved in lipid metabolism (eg, ACE, interleukin-6). Of the remaining 22 genes, only five had not been analysed in the present study (ie, APOH, APOA2, FABP2, FATP, VLDLR). Besides these 17 genes, we also analysed three additional genes involved in lipid metabolism (ie, LCAT, PON1 and PON2). Therefore, the most important candidate genes were included in the present study. Nevertheless, there could be a number of reasons why only a minor part of variation in TG levels could be explained in our study. 
Probably environmental factors are very important in determining variation in TG levels and the heritability of more than $50 \%$ may be an overestimation. Possibly, (complex) gene-gene interactions or presently unknown genes influence plasma TG levels. The REGRESS study was conducted to evaluate the effect of pravastatin, a lipidlowering drug. In the present study, baseline TG values were used for analyses, so the results are not biased by the treatment effect.

In conclusion, significant evidence for statistically independent effects of gene variants in the APOA1 and $L P L$ gene on fasting plasma levels of TG has been provided by this study. However, only a small part of variation in TG levels could be explained by the gene variants. Therefore, it can be concluded that a large part of the variation in TG is caused by environmental factors and unknown gene variants.

\section{Acknowledgements}

JW Jukema is an established clinical investigator of the Netherlands Heart Foundation (2001 D032), The Hague, the Netherlands and MWT Tanck was financially supported by the Netherlands Heart Foundation Grant No. 2000.125.

\section{References}

1 Cullen P: Evidence that triglycerides are an independent coronary heart disease risk factor. Am J Cardiol 2000; 86: 943-949.

2 Gurr MI: Fats; in Garrow JS, James WPT, Ralph A (eds): Human nutrition and dietetics. Edinburgh: Churchill Livingstone, 2000, pp $97-120$.

3 Mead JR, Irvine SA, Ramji DP: Lipoprotein lipase: structure, function, regulation, and role in disease. J Mol Med 2002; 80: $753-769$.

4 Attie AD, Kastelein JP, Hayden MR: Pivotal role of ABCA1 in reverse cholesterol transport influencing HDL levels and susceptibility to atherosclerosis. J Lipid Res 2001; 42: 1717-1726.

5 Oram JF, Lawn RM: ABCA1. The gatekeeper for eliminating excess tissue cholesterol. J Lipid Res 2001; 42: 1173-1179.

6 Barter PJ, Brewer Jr HB, Chapman MJ, Hennekens CH, Rader DJ, Tall AR: Cholesteryl ester transfer protein: a novel target for raising HDL and inhibiting atherosclerosis. Arterioscler Thromb Vasc Biol 2003; 23: 160-167.

7 Snieder H, van Doornen LJ, Boomsma DI: Dissecting the genetic architecture of lipids, lipoproteins, and apolipoproteins: lessons from twin studies. Arterioscler Thromb Vasc Biol 1999; 19: $2826-2834$.

8 Wittrup HH, Tybjaerg-Hansen A, Nordestgaard BG: Lipoprotein lipase mutations, plasma lipids and lipoproteins, and risk of ischemic heart disease. A meta-analysis. Circulation 1999; 99: 2901-2907.

9 Talmud PJ, Hawe E, Martin S et al: Relative contribution of variation within the APOC3/A4/A5 gene cluster in determining plasma triglycerides. Hum Mol Genet 2002; 11: 3039-3046.

10 Kastelein JJ, Ordovas JM, Wittekoek ME et al: Two common mutations (D9N, N291S) in lipoprotein lipase: a cumulative analysis of their influence on plasma lipids and lipoproteins in men and women. Clin Genet 1999; 56: 297-305.

11 Arya R, Duggirala R, Williams JT, Almasy L, Blangero J: Power to localize the major gene for disease liability is increased after accounting for the effects of related quantitative phenotypes. Genet Epidemiol 2001; 21 (Suppl 1): S774-S778.
12 Hauser ER, Hsu FC, Daley D et al: Effects of covariates: a summary of Group 5 contributions. Genet Epidemiol 2003; 25 (Suppl 1): S43-S49.

13 Draper NR, Smith H: Applied regression analysis. New York: John Wiley \& Sons, 1981.

14 Jukema JW, Bruschke AV, van Boven AJ et al: Effects of lipid lowering by pravastatin on progression and regression of coronary artery disease in symptomatic men with normal to moderately elevated serum cholesterol levels. The Regression Growth Evaluation Statin Study (REGRESS). Circulation 1995; 91: $2528-2540$

15 Cheng S, Grow MA, Pallaud C et al: A multilocus genotyping assay for candidate markers of cardiovascular disease risk. Genome Res 1999; 9: 936-949.

16 Pennacchio LA, Olivier M, Hubacek JA et al: An apolipoprotein influencing triglycerides in humans and mice revealed by comparative sequencing. Science 2001; 294: 169-173.

17 Clee SM, Zwinderman AH, Engert JC et al: Common genetic variation in ABCA1 is associated with altered lipoprotein levels and a modified risk for coronary artery disease. Circulation 2001; 103: $1198-1205$.

18 Zwarts $\mathrm{KY}$, Clee SM, Zwinderman $\mathrm{AH}$ et al: ABCA1 regulatory variants influence coronary artery disease independent of effects on plasma lipid levels. Clin Genet 2002; 61: 115-125.

19 Klerkx AH, Tanck MW, Kastelein JJ et al: Haplotype analysis of the CETP gene: not TaqIB, but the closely linked $-629 \mathrm{C} \rightarrow \mathrm{A}$ polymorphism and a novel promoter variant are independently associated with CETP concentration. Hum Mol Genet 2003; 12: $111-123$.

20 Jansen $\mathrm{H}$, Verhoeven AJ, Weeks L et al: Common C-to-T substitution at position -480 of the hepatic lipase promoter associated with a lowered lipase activity in coronary artery disease patients. Arterioscler Thromb Vasc Biol 1997; 17: 2837-2842.

21 Flavell DM, Pineda TI, Jamshidi Y et al: Variation in the PPARalpha gene is associated with altered function in vitro and plasma lipid concentrations in Type II diabetic subjects. Diabetologia 2000; 43: 673-680.

22 Lutucuta S, Ballantyne CM, Elghannam H, Gotto Jr AM, Marian AJ: Novel polymorphisms in promoter region of ATP binding cassette transporter gene and plasma lipids, severity, progression, and regression of coronary atherosclerosis and response to therapy. Circ Res 2001; 88: 969-973.

23 Stocks J, Cooke CJ, Miller NE: A common lecithin: cholesterol acyltransferase gene variant (Ser208 $\rightarrow$ Thr). Atherosclerosis 2000; 149: 219-220.

24 Kamboh MI, Aston CE, Nestlerode CM, McAllister AE, Hamman RF: Haplotype analysis of two APOA1/MspI polymorphisms in relation to plasma levels of apo A-I and HDL-cholesterol. Atherosclerosis 1996; 127: 255-262.

25 Guerra R, Wang J, Grundy SM, Cohen JC: A hepatic lipase (LIPC) allele associated with high plasma concentrations of high density lipoprotein cholesterol. Proc Natl Acad Sci USA 1997; 94: $4532-4537$

26 Acton S, Osgood D, Donoghue M et al: Association of polymorphisms at the SR-BI gene locus with plasma lipid levels and body mass index in a white population. Arterioscler Thromb Vasc Biol 1999; 19: 1734-1743.

27 Leus FR, Zwart M, Kastelein JJ, Voorbij HA: PON2 gene variants are associated with clinical manifestations of cardiovascular disease in familial hypercholesterolemia patients. Atherosclerosis 2001; 154: 641-649.

28 Karpe F, Lundahl B, Ehrenborg E, Eriksson P, Hamsten A: A common functional polymorphism in the promoter region of the microsomal triglyceride transfer protein gene influences plasma LDL levels. Arterioscler Thromb Vasc Biol 1998; 18: 756-761.

29 Peacock RE, Hamsten A, Nilsson-Ehle P, Humphries SE: Associations between lipoprotein lipase gene polymorphisms and plasma correlations of lipids, lipoproteins and lipase activities in young myocardial infarction survivors and age-matched healthy individuals from Sweden. Atherosclerosis 1992; 97: 171-185. 
30 Miserez AR, Schuster H, Chiodetti N, Keller U: Polymorphic haplotypes and recombination rates at the LDL receptor gene locus in subjects with and without familial hypercholesterolemia who are from different populations. Am J Hum Genet 1993; 52: $808-826$.

31 Kuivenhoven JA, de Knijff P, Boer JM et al: Heterogeneity at the CETP gene locus. Influence on plasma CETP concentrations and HDL cholesterol levels. Arterioscler Thromb Vasc Biol 1997; 17: 560-568.

32 Hobbs HH, Esser V, Russell DW: AvaII polymorphism in the human LDL receptor gene. Nucleic Acids Res 1987; 15: 379.

33 Hoh J, Wille A, Zee R et al: Selecting SNPs in two-stage analysis of disease association data: a model-free approach. Ann Hum Genet 2000; 64: 413-417.

34 Pritchard JK, Stephens M, Donnelly P: Inference of population structure using multilocus genotype data. Genetics 2000; 155: 945-959.

35 Xu CF, Talmud P, Schuster H, Houlston R, Miller G, Humphries S: Association between genetic variation at the APO AI-CIII-AIV gene cluster and familial combined hyperlipidaemia. Clin Genet 1994; 46: 385-397.

36 Larson IA, Ordovas JM, Barnard JR et al: Effects of apolipoprotein A-I genetic variations on plasma apolipoprotein, serum lipoprotein and glucose levels. Clin Genet 2002; 61: 176-184.

37 Kamboh MI, Bunker CH, Aston CE, Nestlerode CS, McAllister AE, Ukoli FA: Genetic association of five apolipoprotein polymorphisms with serum lipoprotein-lipid levels in African blacks. Genet Epidemiol 1999; 16: 205-222.

38 Yamamoto M, Morita SY, Kumon M et al: Effects of plasma apolipoproteins on lipoprotein lipase-mediated lipolysis of small and large lipid emulsions. Biochim Biophys Acta 2003; 1632: 31-39.

39 Danek GM, Valenti M, Baralle FE, Romano M: The A/G polymorphism in the -78 position of the apolipoprotein A-I promoter does not have a direct effect on transcriptional efficiency. Biochim Biophys Acta 1998; 1398: 67-74.

40 Angotti E, Mele E, Costanzo F, Avvedimento EV: A polymorphism $(\mathrm{G} \rightarrow \mathrm{A}$ transition) in the -78 position of the apolipoprotein A-I promoter increases transcription efficiency. I Biol Chem 1994; 269: $17371-17374$.

41 Juo SH, Wyszynski DF, Beaty TH, Huang HY, Bailey-Wilson JE Mild association between the A/G polymorphism in the promoter of the apolipoprotein A-I gene and apolipoprotein A-I levels: a meta-analysis. Am J Med Genet 1999; 82: 235-241.

42 Arca M, Campagna F, Montali A et al: The common mutations in the lipoprotein lipase gene in Italy: effects on plasma lipids and angiographically assessed coronary atherosclerosis. Clin Genet 2000; 58: 369-374.

43 Fisher RM, Mailly F, Peacock RE et al: Interaction of the lipoprotein lipase asparagine $291 \rightarrow$ serine mutation with body mass index determines elevated plasma triacylglycerol concentrations: a study in hyperlipidemic subjects, myocardial infarction survivors, and healthy adults. J Lipid Res 1995; 36: 2104-2112.

44 Razzaghi H, Aston CE, Hamman RF, Kamboh MI: Genetic screening of the lipoprotein lipase gene for mutations associated with high triglyceride/low HDL-cholesterol levels. Hum Genet 2000; 107: 257-267.

45 Ferencak G, Pasalic D, Grskovic B et al: Lipoprotein lipase gene polymorphisms in Croatian patients with coronary artery disease. Clin Chem Lab Med 2003; 41: 541-546.

46 Wittrup $\mathrm{HH}$, Tybjaerg-Hansen A, Abildgaard S, Steffensen $\mathrm{R}$, Schnohr P, Nordestgaard BG: A common substitution (Asn291Ser) in lipoprotein lipase is associated with increased risk of ischemic heart disease. J Clin Invest 1997; 99: 1606-1613.

47 Fisher RM, Humphries SE, Talmud PJ: Common variation in the lipoprotein lipase gene: effects on plasma lipids and risk of atherosclerosis. Atherosclerosis 1997; 135: 145-159.

48 Dallongeville J, Meirhaeghe A, Cottel D, Fruchart JC, Amouyel P, Helbecque N: Gender related association between genetic variations of APOC-III gene and lipid and lipoprotein variables in northern France. Atherosclerosis 2000; 150: 149-157.

49 Salah D, Bohnet K, Gueguen R, Siest G, Visvikis S: Combined effects of lipoprotein lipase and apolipoprotein E polymorphisms on lipid and lipoprotein levels in the Stanislas cohort. J Lipid Res 1997; 38: 904-912. 